\title{
Investigation of metallurgical and mechanical properties of 21st century nickel-based superalloy 686 by electron beam welding technique
}

\author{
B ARULMURUGAN ${ }^{1}, \mathrm{M}_{\text {AGILAN }}^{2}, \mathrm{~S} \mathrm{JEROME}^{3}, \mathrm{M}$ ARIVARASU$^{4}, \mathrm{M}$ MANIKANDAN $^{1, *}$, \\ A SRIKANTH ${ }^{1}$ and $\mathrm{N}$ ARIVAZHAGAN ${ }^{1}$ \\ ${ }^{1}$ School of Mechanical Engineering, Vellore Institute of Technology (VIT), Vellore 632014, India \\ ${ }^{2}$ Materials Processing Research Group, Vikram Sarahbai Space Center, Indian Space Research Organization \\ (ISRO), Trivandrum, India \\ ${ }^{3}$ Department of Metallurgical and Materials Engineering, National Institute of Technology, Tiruchirappalli, \\ India \\ ${ }^{4}$ Centre for Innovative Manufacturing Research, Vellore Institute of Technology (VIT), Vellore 632014, India \\ e-mail: mano.manikandan@gmail.com
}

MS received 24 May 2017; revised 12 January 2018; accepted 1 February 2018; published online 27 June 2018

\begin{abstract}
Electron Beam Welding (EBW) was performed on the highly corrosion resistance superalloy 686. The present research work investigates the metallurgical and mechanical properties of the weld joint fabricated by Electron Beam Welding technique, and the results are compared with the base metal. Optical and Scanning Electron Microscope (SEM) analysis were carried out to study the structural properties of the weld joint. The fine equiaxed dendritic structure was revealed in the Center Fusion Zone (CFZ). The columnar dendrite was noticed in the Transition Fusion Zone (TFZ). Energy-dispersive X-ray spectroscopy (EDS) analysis results show that segregation of Mo and W were noticed in the sub-grain boundary. X-ray diffraction analysis (XRD) confirmed the presence of Mo and $\mathrm{W}$ rich phases in the weldment. Tensile testing was carried out to evaluate the strength and ductility of the weld joint. The result revealed that the weld strength was equal to the base metal strength. The presence of Mo and W-rich intermetallic phase reduced the ductility and toughness of the weld joint compared to base metal. Bend test confirmed the defect-free weld joint that was achieved in the Electron Beam Welding technique. The corrosion rate of base metal and EBW weldment are calculated in the synthetic seawater environment with the help of Potentiodynamic polarization experiment, and corrosion rate is measured with Tafel's interpolation technique. The corrosion test result shows that the resistance of EBW weldment is lesser than base metal corrosion resistance because of the microsegregation of alloying elements in the interdendritic region.
\end{abstract}

Keywords. Alloy 686; electron beam welding; microsegregation.

\section{Introduction}

Alloy 686 is a nickel-based superalloy derived from $\mathrm{Ni}-\mathrm{Cr}-$ Mo ternary system [1]. The major alloying elements are $\mathrm{Cr}$, $\mathrm{Mo}$, and $\mathrm{W}$ offering outstanding corrosion resistance in the broad range of service environments. Alloy 686 is highly corrosion resistant alloy, and it is workhorse material for the pollution control (Flue Gas Desulfurization), chemical processing, pulp and paper manufacturer, waste management and marine/naval applications [2]. This alloy exhibits excellent corrosion resistance to seawater [3]. Hence, it plays a significant role in marine applications. Special Metals Corporation [3] evaluated the corrosion behavior of

*For correspondence alloy 686 in the saltwater environments with great detail. Resistance to crevice corrosion was assessed by chlorinated seawater, quiescent seawater, and flowing seawater. The results demonstrated that alloy 686 showed more corrosion resistance compared to alloy $625, \mathrm{C}-276$ and did not crevice corrode. Critical pitting and critical crevice temperature test was conducted as per ASTM G48 C andD methods with 6\% Ferric Chloride Solution. Alloy 686 shows higher resistance to pitting and crevice compared to the alloy $625, \mathrm{C}-276$, 825 and AISI 316 [3].

The welding process plays a significant role in Alloy 686 for the industrial applications. Resistance to corrosion on welding of this alloy received limited attention on the other hand. Welding of this alloy is possible by conventional arc welding process [3]. However, redistribution of alloying 
elements in the fusion zone compromises local corrosion resistance in the conventional arc welding [4]. Many literature study revealed that microsegregation of molybdenum (Mo) that occur in Ni-Cr-Mo based superalloys lead to a situation where dendritic cores are impoverished in Mo and enriched in interdendritic regions $[5,6]$. The microsegregation occurred within the dendritic regions ends with reduced corrosion resistance compared to the base metal.

A solution has been found that proper selection of welding consumables (overalloyed filler wire) and process to combat this phenomenon. Over alloyed filler metals are typically not available for the highly alloyed $\mathrm{Ni}-\mathrm{Cr}-\mathrm{Mo}$ alloys because a higher overall alloy content tends to promote the formation of detrimental intermetallic phases [7]. In some cases, these issues can be resolved by welding these alloys by high power density processes such as electron beam welding and laser welding technique [4]. These welding processes can be used to restore the corrosion resistance in the fusion zone without the addition of filler material. High-density welding method accurately controls the solidification parameters both solidification velocity and temperature gradient to induce dendrite tip undercooling concomitant dendrite core enrichment [4].

Formation of hot cracking in the weld is a critical issue of Ni-Cr-Mo based superalloy. Cieslak et al [8] carried out the varestraint test for GTA welded alloy C-276, C-22, and C-4 grades and found that these alloys are susceptible to hot cracking. The chemical composition of the alloy 686 is almost similar to these grades. The authors characterized material by the electron microscopy technique and concluded that microsegregation of Mo and W led to form the intermetallic secondary solidification constituents (P and $\mu$ ) that are widely responsible for the hot cracking in these grades.

Manikandan et al [9] studied the metallurgical and mechanical properties of alloy C-276 fabricated by continuous Nd: YAG welding technique and observed that the microsegregation of Mo is suppressed when compared to the arc welding method. Guangyi et al [10] investigated the microsegregation of alloy C-276 fabricated by pulsed laser welding method and found no evidence of microsegregation in the fusion zone. Hasim et al [11] studied the laser surface modification of alloy C-276 and reported the absence of microsegregation in the laser treated area. Ahmad et al [12] investigated the electron beam welding of alloy C-276 and obtained the weld joint without any harmful intermetallic compounds. A comparative study reported by Radhakrishna et al [13] for the alloy 718 joints by GTAW and EBW, concluded that rapid solidification obtained by EBW could lead to reduced elemental segregation in the weld joint compared to GTAW.

There is no published literature reported on the alloy 686 fabricated by a high-density welding process such as electron beam welding technique. The present study is to investigate the metallurgical, mechanical properties and corrosion behavior of electron beam welded joint with particular reference to the extent of microsegregation in the fusion zone. The present research work aims to bridge this knowledge gap.

\section{Experimental procedure}

A $3 \mathrm{~mm}$ thick alloy 686 was procured in the form of hotrolled solution annealed condition. The major compounds of the alloy are $\mathrm{Ni}-19 \% \mathrm{Cr}-15 \% \mathrm{Mo}-3 \% \mathrm{~W}-2 \% \mathrm{Fe}$. Weld joint was fabricated by EO PATON Electron Beam Welding (EBW) machine having a capacity of $6 \mathrm{~kW}$ power and $60 \mathrm{kV}$ Voltage. The weld coupons were cut in the dimensions of $3 \mathrm{~mm} \times 55 \mathrm{~mm} \times 160 \mathrm{~mm}$ by using wire cut electro-discharge machining (EDM) process. Figure 1 shows the weld plate photograph of alloy 686 fabricated by EBW. The edges are adequately cleaned with acetone. A bead established the process parameters on trial runs. Six levels of the welding current and five levels of travel speed were varied. A total of thirty trials were conducted, and the optimized parameters are $50 \mathrm{~mA}$ current with the welding speed of $25 \mathrm{~mm} / \mathrm{sec}$ and $60 \mathrm{kV}$ voltage. The macro examination was carried out to ensure the defect-free weld joint achieved by the established process parameters. Microstructure evaluations have been conducted in the regions composed of fusion zone, Heat Affected Zone (HAZ) and base metal. Standard metallographic procedures were adapted to polish the specimen from 220 to 2000 grit $\mathrm{SiC}$ papers followed by $0.5 \mu \mathrm{m}$ alumina powder and water polish. To reveal the microstructure, the sample was etched electrolytically (2 V for 15-20 s) with $10 \%$ wt. Chromic acid solution. Energy Dispersive Spectroscopy (EDS) analysis was carried out to evaluate the microsegregation of alloying elements in the fusion zone. EDS analysis was performed using SEM equipped with EDS facility. SEM/ EDS analysis was conducted using Carl Zeiss (SUPRA 55) equipped with Oxford Instrument EDAX. The analysis was carried out at an accelerating voltage and probe current of $15 \mathrm{kV}$ and $20 \mathrm{nA}$, and a working distance of $10 \mathrm{~mm}$. The tensile test has been conducted as per the ASTM E8 to

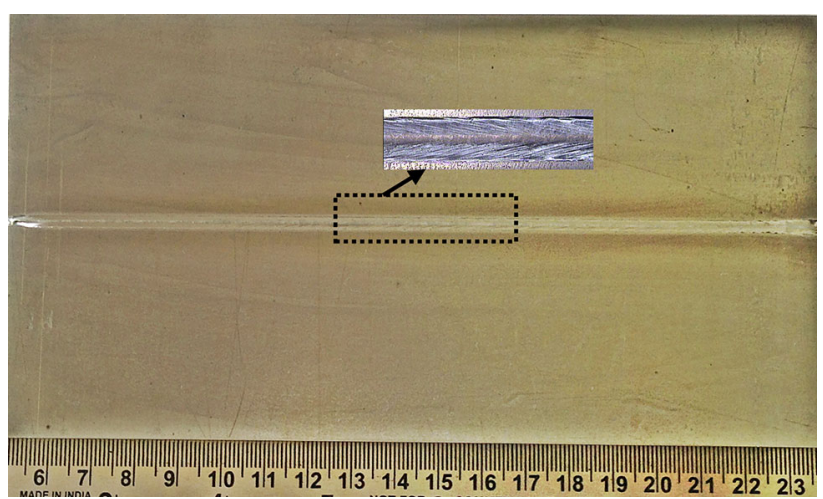

Figure 1. Photograph of as-welded alloy 686 fabricated by electron beam welding technique. 
evaluate the strength of the weld joint. Impact test was done as per the ASTM E23 to assess the toughness of the weld joint. Weld coupons were prepared to cut axis perpendicular to the weld line. Tests were done in triplicate to ensure the reproducibility of the results. Fractographic analysis was carried out using SEM to evaluate the mode of fracture in both tensile and impact tests. Root bend test was carried out as per the ASTM E190 to assess the quality of the weld joint.

An Electrochemical-Potentiodynamic polarization corrosion study was performed on the base metal of alloy 686 and EB weldment with the aid of electrochemical corrosion analyzer (Make: $\mathrm{CH}$ instruments). The weldment cap surface with an exposed area of $1 \mathrm{~cm}^{2}$ was utilized for corrosion study and the remaining portions were covered with insulation tape. ASTM D1141-2013 standard was followed in the preparation of synthetic sea water environment. As per ASTM G59-97(2014) standard, the potentiodynamic polarization testing was carried out. In this method, the test sample was considered as a working electrode, platinum wire acted as a counter electrode and saturated calomel electrode was utilized as a reference electrode. The working electrode and reference electrode were kept closer to minimize the IR drop (potential drop due to solution resistance). Before starting the test, the working electrode was immersed in the corrosive solution for $20 \mathrm{~min}$ to attain the steady state open circuit potential (OCP). Tafel polarization curves contain the details of changes in cathodic to the anodic direction, corrosion potentials, and corrosion current densities. It is also the measure of corrosion rate of the weldment, and it is recorded at a scanning rate of $1 \mathrm{mV} \mathrm{s}^{-1}$, initiated below $(\mathrm{OCP} \pm 200 \mathrm{mV})$.

\section{Results and discussion}

\subsection{Metallurgical property}

3.1a Macro examination: Macroscopic examination was conducted at $50 \times$ magnification to evaluate the welding defects in the weld joint during fabrication. Figure 2 shows the macrograph of weld joint fabricated by electron beam technique. The macrostructure shows the nail-like profile of the weld bead obtained in the electron beam welding. The macrograph indicates that there is no evidence for a crack, undercut and lack of penetration in the fusion zone of the weld joint. The defect-free welding clearly shows the process parameter employed in the present study is optimum. The higher weld speed obtained in the EB resulted in the narrow weld bead in the fusion zone [14]. The columnar orientation in the fusion zone (figure 1) of the weld joint indicates the direction of faster heat dissipation during fabrication.

3.1b Microstructure examination: Alloy 686 plate was received in solution annealed condition. Solution annealing

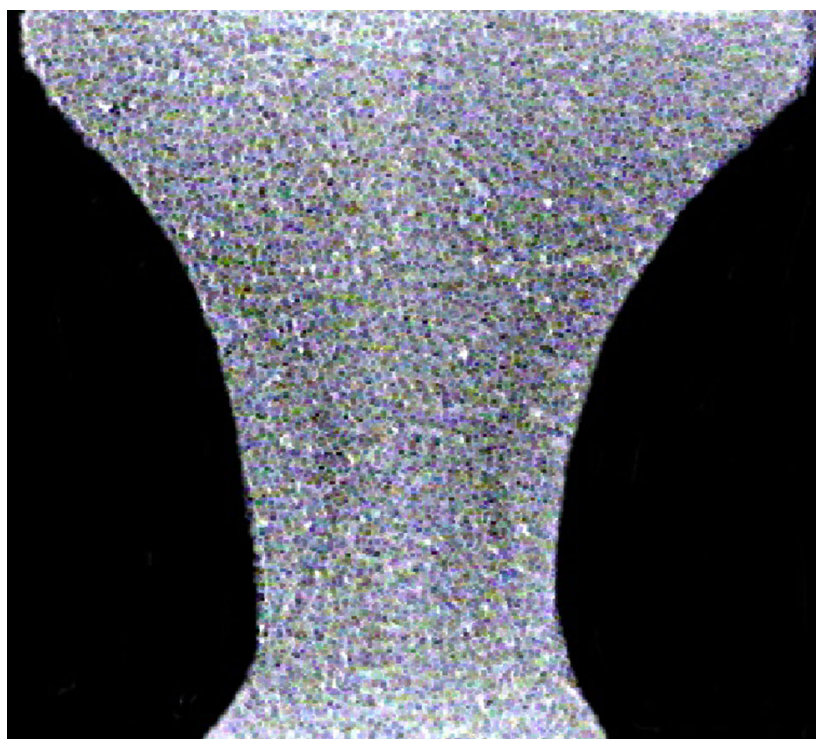

Figure 2. Macrograph of superalloy 686.

assured the alloying elements being dissolved in the austenitic matrix, and the material is free from embrittling phases. The base metal microstructure consists of equiaxed grains with clear grain boundaries (figure 3c). Annealing twins can be seen in several grains. Microstructure examination was carried out in three regions based on the futures on grain orientation: (i) Center Fusion Zone (CFZ), (ii) Transition Fusion Zone (TFZ) and (iii) Edge Fusion Zone (EFZ). Figure 3a represents the CFZ which is located in the center of the top surface. The fine equiaxed grain structure attributed in the CFZ can be the rapid solidification, causes faster cooling rate which delays the grain growth [15]. The section which is adjacent to CFZ was TFZ. Figure $3 b$ represents TFZ. The microstructure consists of smaller dendritic arm spacing which results in finer grain dendritic microstructure. The variation in the grain structures from equiaxed and columnar dendrites resulted in a thermal gradient. Thermal gradients in a weld pool are steeper at regions close to fusion boundary than in weld interior. The steep thermal gradients prevailing at the fusion boundary favor columnar dendritic growth in a direction opposite to that of heat extraction [16]. It is also evident from the weld plate photograph that the columnar growth is flowing towards the fusion boundary. Figure $3 \mathrm{c}$ represents the TFZ. The TFZ is located between the base metal and TFZ. The microstructure consists of planar and cellular exist at the solidliquid interface region. It is not easy to distinguish the cellular structure due to adjoining the columnar dendrite. This phenomenon reveals that the higher cooling rate with faster solidification [15]. The growth of cellular and planar is suppressed. As a result, the narrow planar and cellular area is presented in the EFZ. The faster solidification also achieved the smaller HAZ adjacent to the weld interface region. 


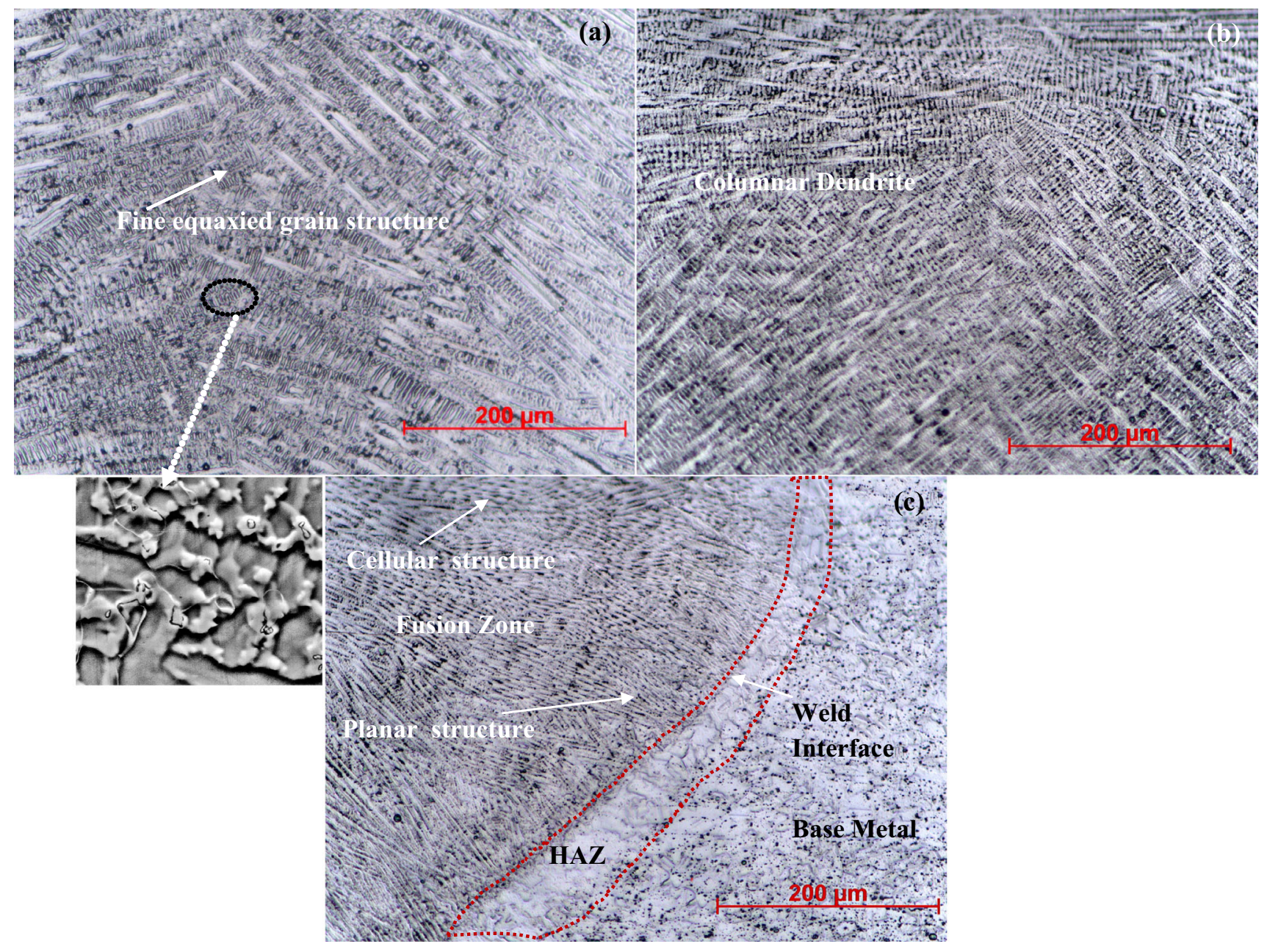

Figure 3. Microstructure of electron beam welded alloy 686 : (a) CFZ, (b) TFZ and (c) EFZ.

3.1c SEM/EDS analysis: Figures 4(a) and (b) show the higher magnification SEM images of fusion zone weld center and weld interface regions. The fusion zone grain boundaries are decorated with the secondary phases in the weld center and interface regions. Microsegregation plays a significant role in the solidification of $\mathrm{Ni}-\mathrm{Cr}-\mathrm{Mo}$ based superalloy. EDS analysis was carried out with emphasis on alloying elements $\mathrm{Cr}$, Mo, and $\mathrm{W}$ with matrix element $\mathrm{Ni}$. These alloying elements are the composition of concern secondary phases $\mathrm{P}$ and $\mu$. So these elements were selected to evaluate the microsegregation in the fusion zone. EDS analysis was carried out in the grain boundary and matrix of the fusion zone. In figure 4, (a)-(b) the regions (i)-(ii) represent the EDS analysis of weld center grain boundary and matrix. It is observed that the alloying elements Mo and $\mathrm{W}$ are enriched and depletion of $\mathrm{Ni}$ in the grain boundary compared to the matrix. Similar observation also noticed in the weld interface regions (figure 4, regions (iii)-(iv). (c)(d)). The EDS result clearly shows that the presence of Mo and W-rich intermetallic phases in the grain boundary region. The elemental analysis results are also plotted in the bar chart (figure 5) and also tabulated for understanding. The X-Ray Diffraction (XRD) analysis also confirms the Mo and W-rich intermetallic phase in the interdendritic region of weldment which is shown in figure 6 .

The tendency of microsegregation can be numerically quantified with the segregation/ distribution coefficient $(\mathrm{k})$ which is derived from Scheil equation [4]. Many researchers used the technique to quantify the microsegregation of NiCrMo based superalloy. Manikandan et al [16] studied the microsegregation of NiCrMo alloy by using the equation:

$$
k=\frac{C_{\text {core }}}{C_{o}}
$$

where $\mathrm{C}_{\text {core }}$ is the elemental level in the dendrite core and $\mathrm{C}_{\mathrm{o}}$ is the elemental level in the nominal composition of the alloy. According to Scheil equation, the extent of microsegregation may be determined entirely by the value of ' $\mathrm{k}$ ' associated with the element of interest. The alloying elements which have a value of $\mathrm{k}<1$ reveal the tendency to 

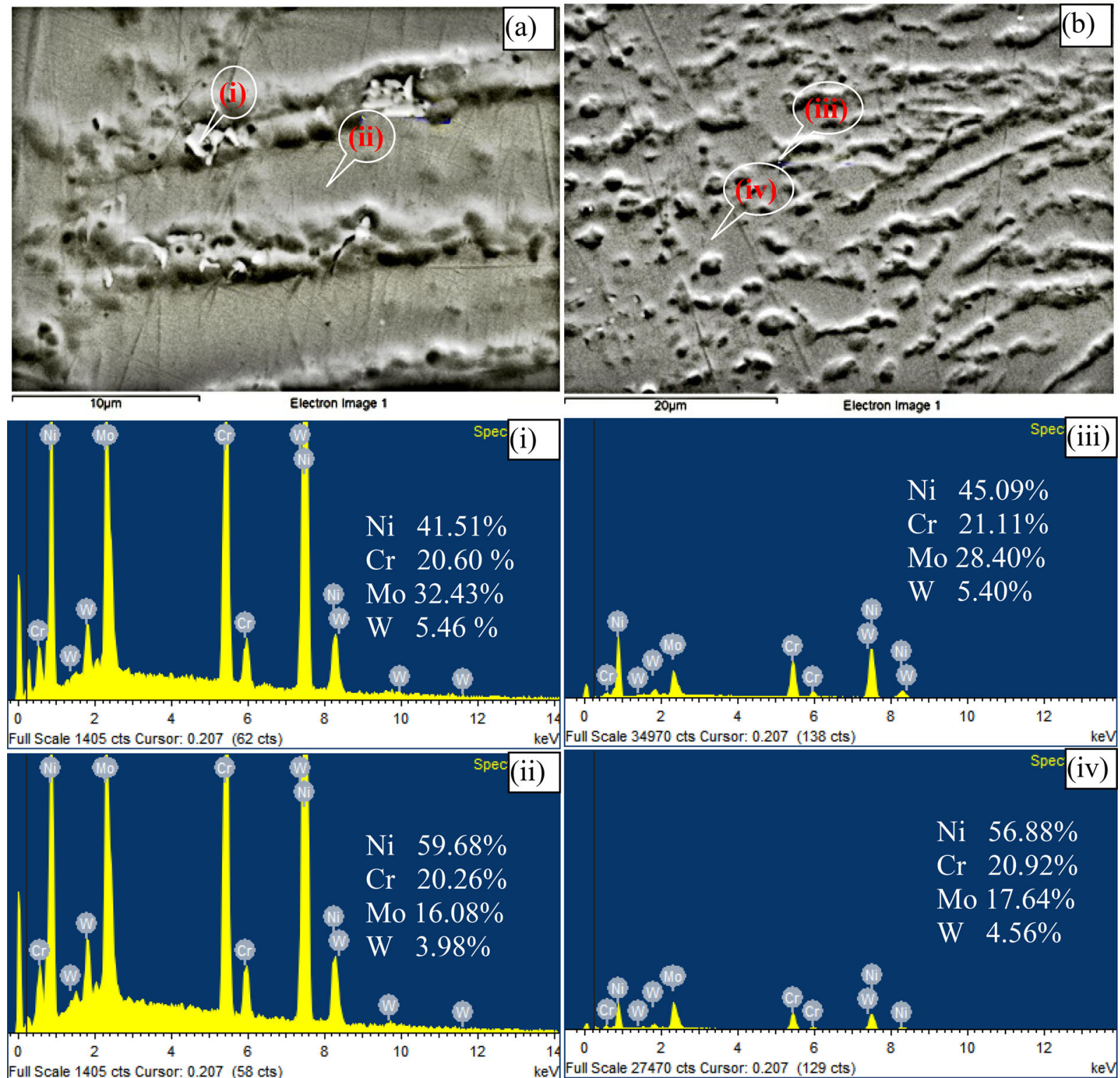

Figure 4. SEM/EDS Analysis of various region of Electron Beam Welded alloy 686; (a) SEM image - Weld Centre, (b) SEM image Weld Interface regions, (i-iv) represent EDS analysis of respective SEM images) (i) Weld Centre Grain boundary, (ii) weld centre Matrix, (iii) weld Interface Grain boundary and (iv) Weld Interface - Matrix.

microsegregation in the interdendritic liquid, whereas the value of $\mathrm{k}>1$ segregates to the dendrite core. The alloying elements $\mathrm{k}<1$ segregate to the interdendritic region are last to solidify and transform to the brittle TCP phases at the end of the solidification [4]. It is observed from EDS analysis of the present study that the chemical composition of $\mathrm{Ni}, \mathrm{Cr}, \mathrm{Mo}$, and $\mathrm{W}$ are closely matched with the chemical composition of $\mathrm{P}$ and $\mu$ phases reported by Cieslak et al [8]. The values of ' $\mathrm{k}$ ' listed in table 1 which shows the microsegregation of Mo and $\mathrm{W}$ are found to be very high. The microsegregation of Mo and $\mathrm{W}$ can be understood in terms of mismatch of atomic radii of Mo and $\mathrm{W}$ with matrix element Ni. The difference is $9 \%$ increase for $\mathrm{Mo}$ and $10 \%$ for $\mathrm{W}$, whereas the segregation of $\mathrm{Cr}$ is not observed in the present study. The atomic radii difference between $\mathrm{Cr}$ and $\mathrm{Ni}$ is $1 \%[1,6]$. The tendency of microsegregation is not active with $\mathrm{Cr}$ element. DuPont [8] also reported that alloying elements are added intentionally to improve the corrosion behavior of the alloy. The compositions of these alloying elements are beyond the solubility limit which leads to the formation of brittle TCP phases during solidification [1]. These phases might act as a source of hot cracking. The present study has not provided any direct evidence for the presence $\mathrm{P}$ and $\mu$ phases. Cieslak et al [8] reported the size of the particles of these phases in order of $0.5 \mu$. The EDS analysis had done in the 


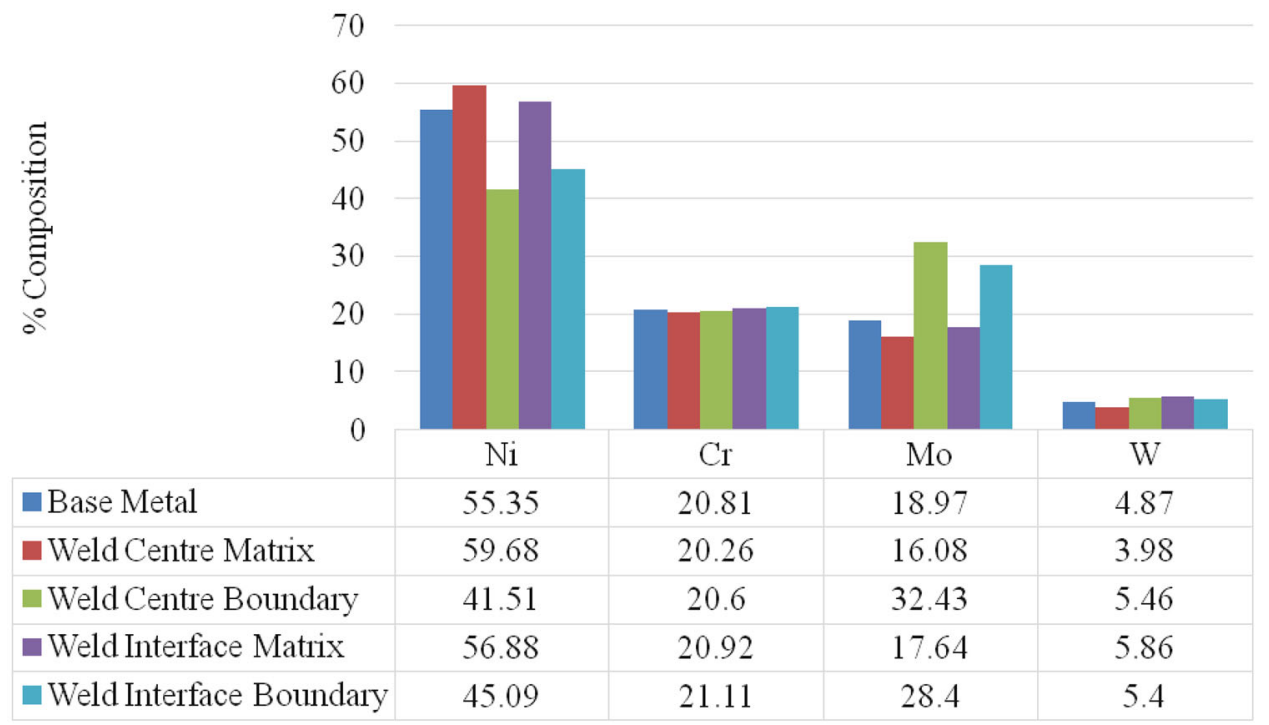

Figure 5. Bar chart representation of EDS analysis.

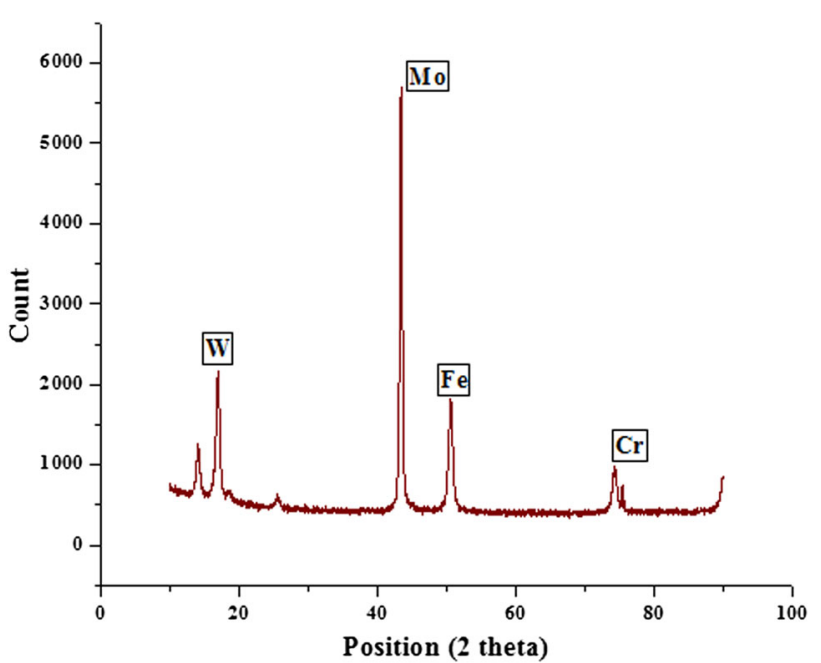

Figure 6. X-Ray Diffraction analysis of Electron beam welded sample.

Table 1. Distribution co-efficient ' $\mathrm{k}$ ' value of alloying elements.

\begin{tabular}{lcccc}
\hline & $\mathrm{Ni}$ & $\mathrm{Cr}$ & $\mathrm{Mo}$ & $\mathrm{W}$ \\
\hline Weld Center (Matrix) & 1.06 & 0.97 & 0.84 & 0.81 \\
\hline
\end{tabular}

present study has no such high resolution to identify such small size. Transmission Electron Microscopy (TEM) analysis will be taken up in the near future. The presence of $\mathrm{P}$ and $\mu$ phases lead to hot cracking at the end of the solidification. As pointed out varestrain test will be taken further to evaluate the susceptibility of hot cracking in the alloy 686 .

\subsection{Mechanical property}

3.2a Tensile examination: The tensile test was carried out to evaluate the strength and ductility of the weld joint. The tensile results are presented in table 2 . The base metal strength and ductility are listed in table for the comparison. Figures 7 and 8 show the tensile failure and tensile graphs of the welded samples, respectively. It is observed from the photograph that the failure occurred in the fusion zone. The results indicate that the strength of the weld joint is matching with the base metal. The weld joint satisfied the minimum strength of the base metal (815 MPa). The fractured surface was evaluated by SEM (figure 9). The fracture exhibited a distinct dendritic pattern that shows clearly that the fracture took place preferentially along the interdendritic region. The ductility of the weld joint is significantly lower than the base metal. In general, \% elongation will be considered when the homogenous material is tested. The weldment consists of three different regimes - base metal, HAZ and fusion zone. The contribution of ductility in each zones will differ. Moreover, microsegregation plays a detrimental role in the fusion zone grain boundaries. The microsegregation ended with the formation of secondary intermetallic phases in the interdendritic region and reduced the ductility of the weld joint. It is also evident from the EDS analysis of the present study reported in section 3.1c DuPont et al [1] also reported that the formation of secondary phases in the $\mathrm{Ni}-\mathrm{Cr}-\mathrm{Mo}$ alloy reduced the ductility and toughness of the weld joint.

3.2b Impact examination: Charpy V-notch test (figure 10) was carried out to evaluate the toughness of the base metal and weld joint, and the values are given in table 2. SEM fractography (figure 11) analysis was done 
Table 2. Cumulative mechanical property of electron beam welded alloy 686 .

\begin{tabular}{|c|c|c|c|c|c|}
\hline \multirow[b]{2}{*}{ Sample no. } & \multicolumn{3}{|c|}{ Tensile test } & \multirow{2}{*}{$\begin{array}{l}\text { Impact test } \\
\text { toughness }(\mathbf{J})\end{array}$} & \multirow[b]{2}{*}{ Bend test } \\
\hline & Ultimate tensile strength (MPa) & Yield strength (MPa) & $\%$ Elongation & & \\
\hline Base metal & 815 & 489 & 60 & 31.4 & No cracks were found \\
\hline Sample 1 & 817 & 465 & 22 & 18.7 & \\
\hline Sample 2 & 810 & 460 & 20 & 17.3 & \\
\hline Sample 3 & 818 & 461 & 21 & 22.1 & \\
\hline Average & 815 & 462 & 21 & 19.3 & \\
\hline
\end{tabular}

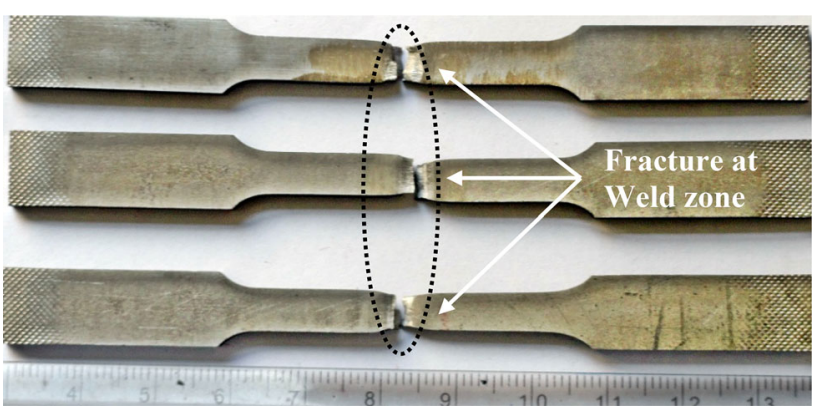

Figure 7. Tensile failure photograph of alloy 686 fabricated by EBW.

to evaluate the mode of fracture. The presence of secondary phases in the weld microstructure is primarily responsible for the inferior toughness than the base metal. The brittle secondary phase particle initiates the early void initiation and links up with the faster propagation of cracks. The secondary phase plays a detrimental role in the interdendritic region as pointed out in the impact study. It is also more evident from the EDS analysis in the present study reported in section $3.1 \mathrm{c}$.

3.2c Bend test: The photograph of bend test specimens fabricated by electron beam welding is shown in figure 12 . It is observed from the pictures that no cracks or fissures were found in weld joints even up to the maximum bending angle of $180^{\circ}$. It is confirmed that the welding tried out in this present study produced jointly with a good degree of formability and freedom from critical defects which can serve as crack nucleation sites during bending. These results are also in agreement with the macro examination of the present investigation.
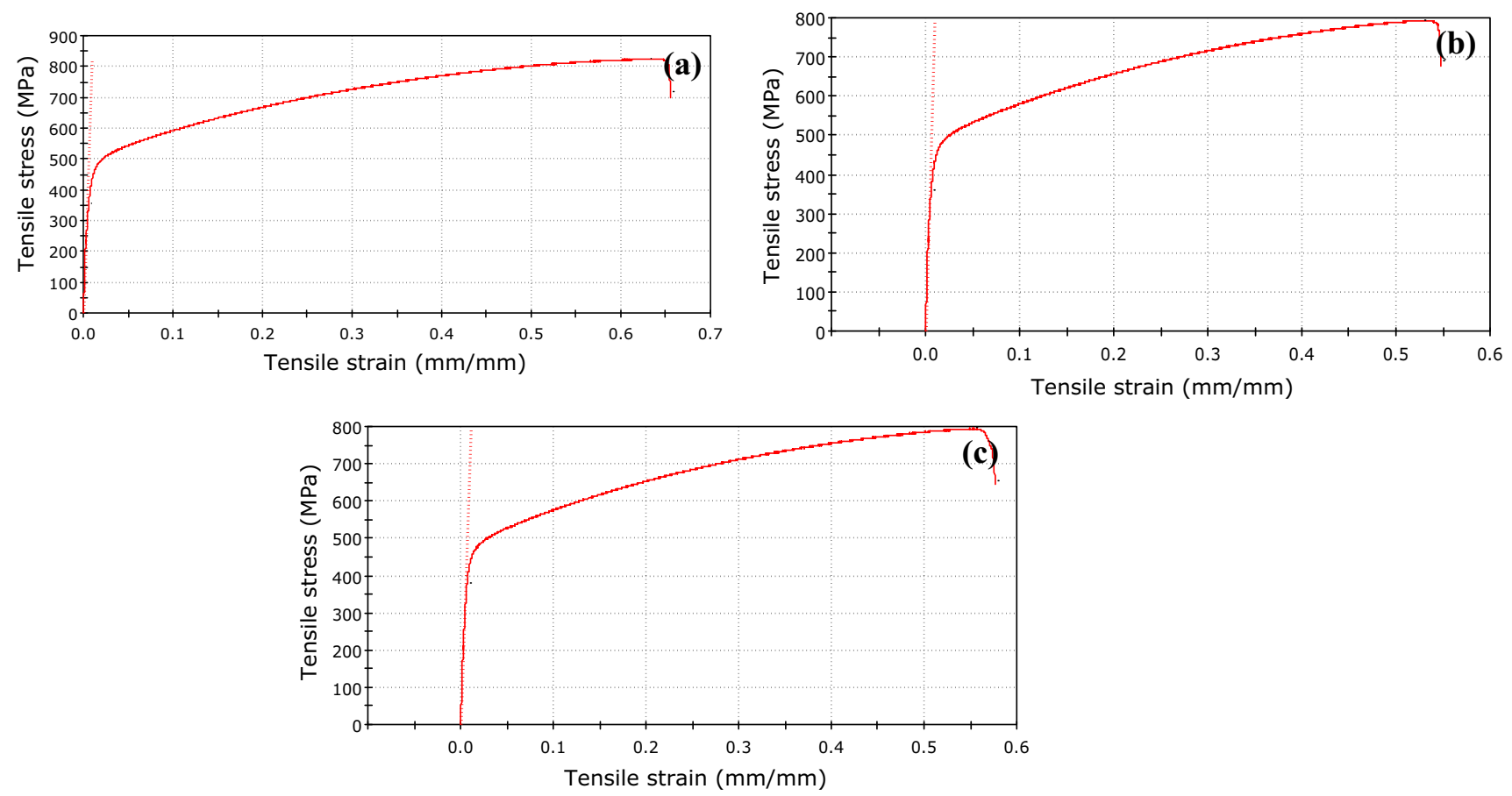

Figure 8. Tensile (Stress Strain) curves of Electron beam welded (a) sample 1, (b) sample 2 and (c) sample 3. 


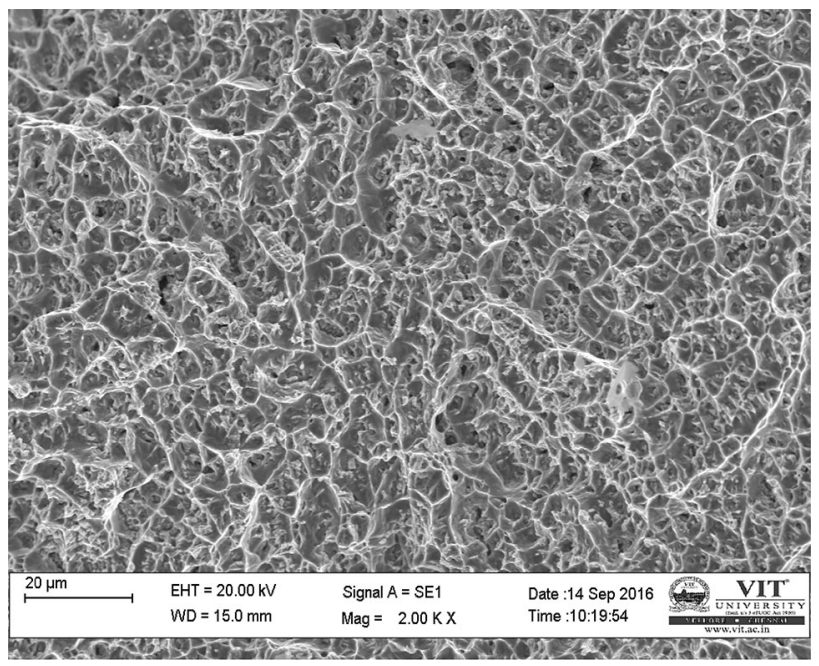

Figure 9. SEM fractograph of tensile failure specimen.

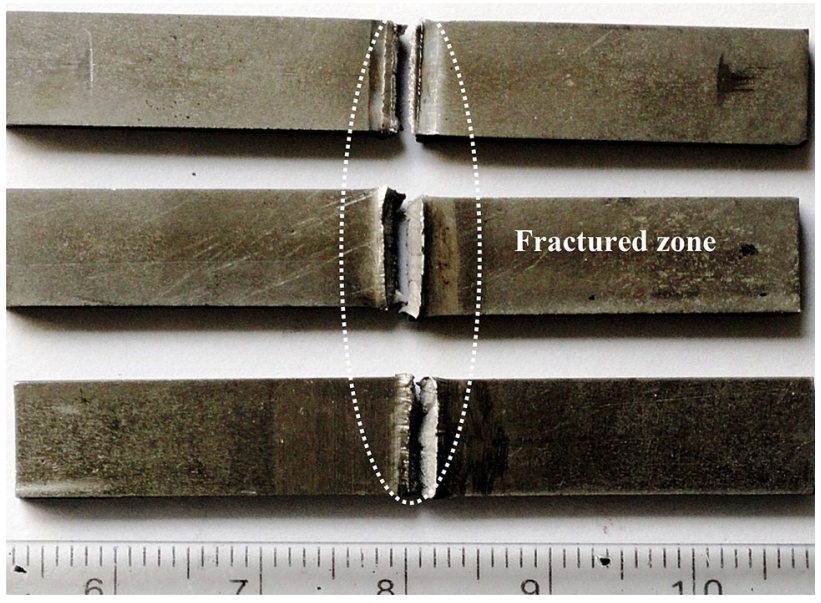

Figure 10. Impact failure samples of alloy 686 by EBW.

\subsection{Corrosion test}

Tafel polarization plots of base metal and welded sample fabricated by EBW technique in synthetic sea water environment are shown in figure 13. The corrosion rate obtained from this plots are $0.15 \mathrm{mpy}$ (mils per year) for weldment and $0.01 \mathrm{mpy}$ for the base metal. It is observed from the plot, that EBW sample's corrosion rate is higher than base metal. As discussed in microstructure examination (section 3.1b), CFZ contains fine equiaxed dendrites; TFZ and EFZ have the coarse cellular and planar dendrites. It shows that there is a non-homogeneity in micro structures observed between center of fusion zone and fusion boundary. But, base metal contains only fine equiaxed grains and homogeneity is also observed all over the microstructure. From the study of Balasubramanian et al [17], it is well-supported that fine equiaxed grain structure offers better corrosion resistance than coarse cellular and planar dendrites structure, because of

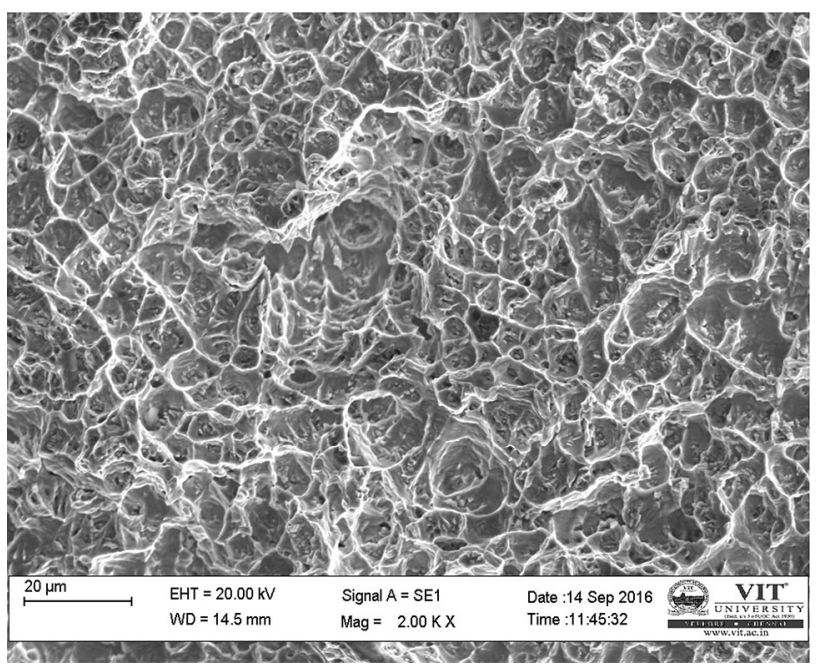

Figure 11. SEM fractrograph of Impact failure specimen.

their uncontrollable grain growth nature. However, in case of EBW sample, during weld solidification, there is a risk of microsegregation. This leads to the formation of secondary TCP brittle phases in the interdendritic regions of the weldment, and it is also well-supported from SEM/EDS analysis. The secondary phases at interdendritic region could speed up corrosion locally and hence corrosion rate is higher in electron beam weld sample. Crum et al [18] and John Dupont et al [1] reported that microsegregation occurs in the weldment of Ni-Cr-Mo alloys could lead to situation where dendrite cores are impoverished in elements like Mo and interdendritic regions are enriched in $\mathrm{Mo}, \mathrm{Nb}$ and sometimes $\mathrm{Cr}$. This segregation within the dendritic structure results in reduced corrosion resistance of the weld joint compared to the wrought base metal and the present study has observed the same.

\section{Conclusion}

Alloy 686 was successfully welded by an electron beam welding technique. The significant outcome of the results is listed below.

1. From the macrostructure, no defects are seen in the weld joint. This confirmed that the process parameters adopted in the present study were good.

2. The faster solidification achieved in the fusion zone induced the equiaxed dendrite structure with a narrow weld bead. The HAZ near fusion zone was narrower due to the low heat input.

3. Scanning Electron microscope study has revealed the presence of secondary phases in the grain boundary. EDS and XRD analysis unveiled the segregation of Mo and $\mathrm{W}$ that could lead to the formation of secondary phase in the fusion zone grain boundary. 


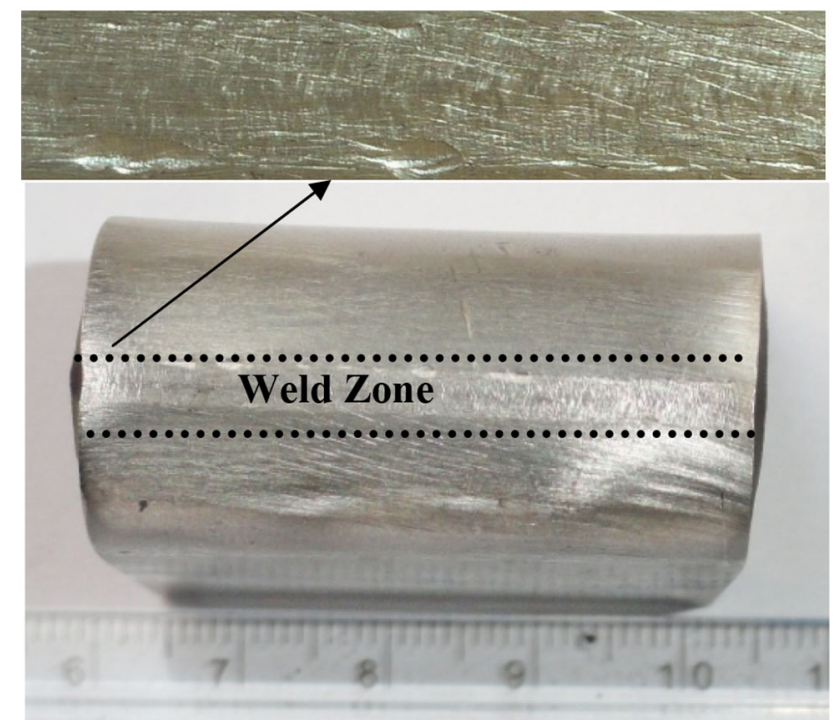

Figure 12. Bend test specimen of alloy 686 fabricated by Electron Beam Welding.

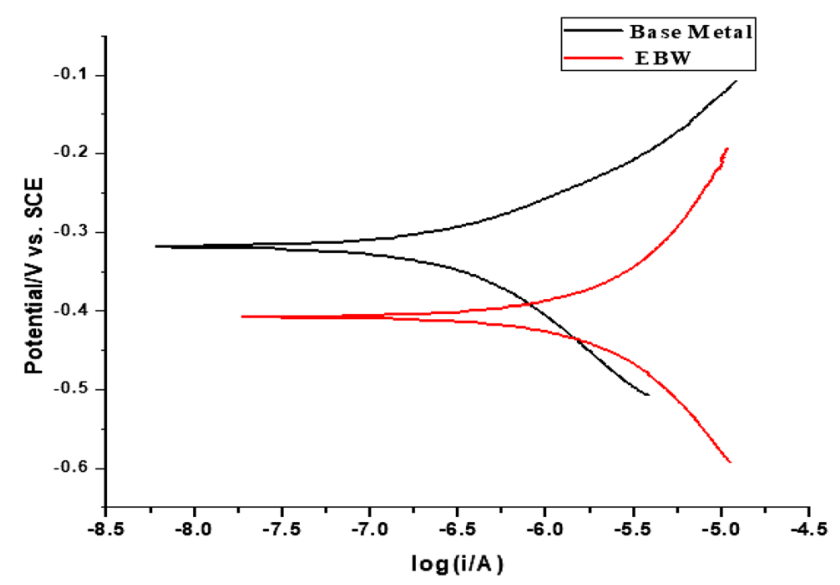

Figure 13. Tafel polarization curves of alloy 686 EBW weldment in synthetic sea water.

4. Weld joint obtained the base metal strength. Presence of secondary phases reduced the ductility and impact toughness of the weld.

5. Bend test did not show any crack in the weld zone. This confirmed the ductility of the weld joint is good.

6. EBW shows higher corrosion rate than the base metal due to microsegregation of Mo-rich intermetallic phases at the interdendritic region.

\section{References}

[1] John Dupoint N, John Lippold C and Samuel Kiser D 1999 Welding metallurgy and weldability of nickel-base alloys. New Jersey: Wiley: 49-51
[2] Inconel alloy 686 The corrosion-resistant alloy for the 21st century. Special Metals. http://216.71.103.52/documents/ Inconel\%20alloy\%20686,\%20a\%20new\%20alloy.pdf. [Accessed 30 June 2015]

[3] Special Metals. http://www.specialmetals.com/assets/docu ments/alloys/inconel/inconel-alloy-686.pdf. [Accessed 30 June 2015]

[4] Perricone M J and Dupont J N 2006 Effect of composition on the solidification behavior of several $\mathrm{Ni}-\mathrm{Cr}-\mathrm{Mo}$ and $\mathrm{Fe}-$ Ni-Cr-Mo alloys. Metall. Mater. Trans. A. 37A: $1267-1280$

[5] Arulmurugan B and Manikandan M 2017 Development of welding technology for improving the metallurgical and mechanical properties of 21st century nickel based superalloy 686. Mater. Sci. Eng. A. A691: 126-140

[6] Manikandan M, Arivazhagan N, Nageswara Rao M and Reddy G M 2014 Microstructure and mechanical properties of alloy C-276 weldments fabricated by continuous and pulsed current gas tungsten arc welding techniques. J. Manuf. Processes, 16: 563-572

[7] Rowe M D, Crook P and Hoback G L 2003 Weldability of a corrosion-resistant Ni-Cr-Mo-Cu alloy. Weld J. 82: 313-320

[8] Cieslak M J, Headley T J and Romig A D 1986 The welding metallurgy of Hastelloy alloy C-4, C-22 and C-276. Metall. Trans. A. 17A: 2035-2047

[9] Manikandan M, Hari P R, Vishnu G, Arivarasu M, Devendranath Ramkumar K, Arivazhagan N, Nageswara Rao M and Reddy G M 1986 Investigation of microstructure and mechanical properties of super alloy C-276 by continuous Nd: YAG laser welding. Procedia Mater. Sci. 17A: 2233-2241

[10] Guangyi M A, Dongjiang W U and Dongming G U O 2011 Segregation characteristics of pulsed laser butt welding of Hastelloy C-276. Metall. Mater. Trans. A 42A: 3853-3857

[11] Hashim M, Sarath Raghavendra Babu K E, Muthukannan Duraiselvam and Harshad Natu 2013 Improvement of wear resistance of Hastelloy C-276 through laser surface melting. Mater. Des. 46: 546-551

[12] Ahmad M, Akhter J I, Akhtar M, Iqbal M, Ahmed E and Choudhry M 2005 Microstructure and hardness studies of the electron beam welded zone of Hastelloy C-276. J. Alloys Compd. 390: 88-93

[13] Radhakrishna C H, Prasad Rao K and Srinivas S 1995 Laves phase in superalloy 718 weld metals. J. Mater. Sci. Lett. 14: 1810-1812

[14] Aman Kaur, Colin Ribton W and Balachandaran 2015 Electron beam characterization methods and devices for welding equipment. J. Mater. Process. Technol. 221: 225-232

[15] Dongjiang M A, Dongjiang W U, Fangyong Niu and Helin Zou 2015 Microstructure evolution and mechanical property of pulsed laser welded Ni-based superalloy. Opt. Lasers Eng. 72: 39-46

[16] Manikandan M, Arivazhagan N, Nageswara Rao M and Reddy G M 2015 Improvement of microstructure and mechanical behavior of gas tungsten arc weldments of alloy C-276 by current pulsing. Acta Metall. Sinica 28: 208-215

[17] Balasubramanian M, Jayabalan V and Balasubramanian V 2008 Effect of pulsed gas tungsten arc welding on corrosion behavior of Ti-6Al-4 V titanium alloy. J. Mater. Des. 29: $1359-1363$ 
[18] Crum J R J, Shoemaker L E and Kiser S D Special alloys and overmatching welding products solve FGD corrosion problems. Special metals welding products, Technical paper. U.K. http://
216.71.103.52/documents/Special\%20Alloys\%20and\%20Over matched $\% 20$ Welding\%20Products $\% 20$ Solve $\% 20$ FGD $\% 20$ Cor rosion\%20Problems.pdf. [Accessed 22 June 2016] 